\title{
Ethics as an Active Self-construction of the Human
}

\author{
Conceição Soares \\ Universidade Católica Portuguesa, Porto, Portugal
}

\begin{abstract}
This paper will attempt to clarify the clear tendency, in our contemporary world, to look at ethics as something that "cures" all wrongs, all unbalance, and all evils from the political, environmental, to the business ones. For this reason, there is nothing better than to turn to ethics in order to "moralise" the system and the world, when the numerous news of fraud, injustice, and scandals are a part of everyday life in the business world and in our society. But, is this the role of ethics? Can we reduce the aim of ethics to a mere technique? In this paper, it is argued that ethics needs to be replaced in the epistemological scale of knowledge, where until now it has occupied a place at the top. Ethics needs to be repositioned in a different level of knowledge where we may find the roots of its foundation. It is also discussed that it is at the core of being that the experience of the action takes place and develops and in it, ethics takes root. Furthermore, it is suggested that understanding ethics from this point of view presupposes a new ethos around a relational poietics which privileges inter-subjectivity, self-creation, and an active and dynamic construction of the human and of the world.
\end{abstract}

Keywords: ethics, ontology, action, relational ethics, human nature, being

\section{Introduction}

Since the end of the 1980s, ethics started to be a part of the companies' agenda and from then on its area of intervention is becoming greater and greater. However, the coming back of ethics to the so-called scientific areas nowadays, makes us wonder, because modern science represented, in a way, a victory from science over ethics, not only because it avoided ethics, but also because that was seen as the only scientific way to progress. That phenomenon was seen in a positive way and it was a manifestation of independence and autonomy. So, one wonders about this coming back of ethics.

We can find an explanation in some epistemological reasons:

- The loss of reference of the so-called natural sciences which had, for a long time, an unconditional value and then started to be looked at with suspicion, particularly in its technical application;

- The disorder and lack of strict rules in some sectors, namely, some scandals which have shaken the business world;

- The need to change human behaviour by clarifying and improving the ethical support, which has in principle its roots in human nature;

- The search for a new ethics, different from the one which science had to decline, with the aim to assert itself.

Conceição Soares, Ph.D., Assistant Professor of Social Philosophy and Ethics, Centro de Estudos em Gestão e Economia-Faculdade de Economia e Gestão do Centro Regional do Porto, Universidade Católica Portuguesa.

Correspondence concerning this article should be addressed to Conceição Soares, Faculdade de Economia e Gestão do Centro Regional do Porto, Universidade Católica Portuguesa Rua Diogo Botelho, 1327/4169 Porto/Portugal. E-mail: csoares@porto.ucp.pt. 
In spite of seeming quite obvious that ethics appears not only as a fundamental reference, but also as the hope for the cure of all evils, we should probably ask ourselves, then, to which ethics should we turn to or which should we choose? If we understand ethics as the only solution to the problems which badly affect the companies, we are just perpetuating of understanding the ethics of western culture since the Greeks. That is, ethics is seen more as a "moral of customs" than as a discipline closely related to the human life and all other beings. In this case, what we are looking for is a scientific reference more than an ethics. But, we can still find another explanation. Ethics is kept within the domains of rationality, although not to maintain the demands of the scientific model, but to establish a new form, status of knowledge in the search for a unity of knowledge. This other vision of ethics which apparently has nothing to do with the first is, in fact, in the same ground, both expecting to be scientifically recognized. Neither a scientific ethics nor a philosophical ethics is able to give an answer to the problems we face today, not only in companies but also in the world.

Therefore, this paper tries to rethink the role of ethics and in particular the role of ethics in our world.

\section{What Is the Role of Ethics}

\section{Scientific Ethics}

In Heidegger's (1948) work The Letter on Humanism, Heidegger stated that:

"Ethics" together with "logic" and "physics" come into fashion for the first time in Plato's school. These disciplines originate at a time when thinking is allowed to become "philosophy", philosophy then becoming $\mid \pi \iota \tau \eta \dot{\mu \eta}$ (science), and science itself becomes a subject in school and school work. (p. 35)

In the Greek world, ethics was directed to adults and it had the same role as logic ruled by clear criteria. In the Greek school, ethics could only be taught as science. This scientific side of ethics had two dimensions:

- Formal aspect-conventionally elaborated by society;

- Operational function - guiding life in an "unfailing", necessary way, trying to avoid not only the sense of responsibility, but also the sense of spontaneity (Gonçalves, 1998).

In the face of a scientific ethics, human beings were submissive and ethics was, indeed, applied to human existence as if it was a technique, withdrawing the creative and free content from the action. The status of ethics became, thus, automatic, replacing risk and the unexpected, manipulating ready-made ideas instead of opening and exploring new ways. Nevertheless, in this manner the status of the "honest man" was safe. School controlled an ancient fear, that of "losing man" and the fear of subjectivity. A school which fears man will try to keep within the parameters of anthropocentrism at all cost, neglecting the difference between subjectivity and subjectivism.

It was this ethics of the Greek school and with these characteristics which reached us and is still in our educational systems. In the face of a world in constant transformation and in which science is not the ultimate reference anymore, ethics turns up as a carving knife which cuts everything unwanted and repair everything that is wrong. It mainly controls what escapes the understanding of a rationality, which most of the times guides itself with a horizontal sense, marked by a total autonomy, trying to link all the elements of the chain with the aim of dominating it and avoiding the entrance of external elements. There is also the need for a vertical sense of rationality, which although not losing its precision, opens up new horizons and does not lose itself so much in the connection between the already existing elements. 


\section{Philosophical Ethics}

Even if we disclaim a scientific ethics and replace it with a philosophical ethics, as we still have it in the western culture, grounded in the human nature, the situation does not change, because ethics remains on the top of the epistemological scale. Western philosophical ethics has two main difficulties which hinder the desired solution: First, the fact we want to ground ethics on the human nature is constrained by cultural impediments which define it; and second, an ethics of nature is always separated from the other natures, not allowing the link between them, unless humanity itself articulates its own specific nature with all the others, only to manipulate or dominate them by an artifice of power.

The difficulties of building an ethics, either scientific or philosophical, are huge, since they appear to be really insufficient to deal with the global tasks with which we are faced today, not only those related to human beings, but also those related to the planet. An ethics that only takes into account the human being cannot give a solution to spheres of reality which surpass it. However, when we put this problem in these terms we are not concerned with which kind of ethics to adopt, but to which knowledge to call for.

\section{Ethics as an Expression of Being}

Nowadays, in spite of the question of ontology being outmoded, the author would like to turn back to it. For a long time ontology has been understood as the source of all immobility, identified as the essence of the natural original forms, that is, as the antithesis of all transformation. To this negative sense of ontology we should add another one with a positive sign, which tells us that the life of being expresses itself through determinations without fixing itself in none of them, pointing to new possibilities and not to finished manifestations or to definitive configurations. It is in action that this positive sense of ontology takes place and in action it makes sense to look at the question of ethics in a different way. To do that one needs to establish a fundamental difference between acting and techne.

In our western culture action has been often confused with techne, contaminating all the complexity of the process of action. Techne, goes hand in hand with a culture which considers life as an often uncontrollable surplus that one needs to control and dominate, appearing as a technique to eradicate all evil. According to Gonçalves (1998):

[...] It is a function of human rationality, not the understanding of the reality with which one could marvel and live in a fraternal way, but the removal of an excess, or if we want to emphasize, the excision of an excrescence, which, by that reason, may be considered as a malefic entity. (p. 20)

If we reduce action to a mere technique, it fulfills such aim. However, the acting cannot be reduced to a mere technique if we take into account mainly the energy of the action itself. If the aim of techne is planned beforehand, which implies the fulfillment of certain functions which are previously calculated, the action manifests itself at the same time it is happening, with the intentionality of expanding its own possibilities as far as possible. As previously mentioned above, as techne always starts from a certain and planned reality, which corresponds to a constructed mental reality, more than a given dynamics, it always impels to the searching of a certain meaning and aim. Unlike techne, in action the fulfillment of the aim only makes sense in relation to the energy of the impulse which has motivated it and which does not follow any external principles.

Scientific ethics, which the author have just mentioned before, can easily be characterized as an action reduced to techne, and to a human techne, as if we were dealing with a technique. But, if one understands ethics as a dimension of the experience of action itself, controlling more than reality, ethics expands that reality, not 
only within the boundaries of human nature, but also in the development of all reality.

Although action is a complex and rich experience of a difficult characterization, it is possible, at least, to underline five of its main specificities:

(1) It is the essential experience of the human being, although it does not just limit itself to the anthropological dimension;

(2) What provides value to the human is the being and not its nature. The human is an adjective expression of being;

(3) It is an exercise of manifestation, of development and affirmation of the value of reality. It demands of the human being, its main protagonist, an attitude of faithfulness to that impetus of being, and it does not reduce it to the perimeter of human nature;

(4) It is an experience of unity and of differentiating unification - part of giving representations, but which opens itself in a renewed way to new manifestations;

(5) It is an experience which places all beings in relation-because the ground is ontological and not anthropological. Human beings are not in relation to other beings as if they were "alter egos" but they are also differentiated and differentiating manifestations of the same being in which they all participate.

Ethics, understood as this experience of being, does not reduce itself to rules or duties, but it points to the movements of openness and development, where what prevails is cooperation and not the insatiable struggle of some which leads to the undermining and even the extermination of others.

\section{The Pertinence of Ethics in Our World}

\section{Ethics as a Relational Poetics}

If it is only possible to build an ethics from the ontological reality and if that ontological reality comes from action one can say that ethics is related to a dynamic activity in the active construction of the human in its relation to all other beings. Each act of being one has the possibility of standing up as a person and this act constitutes our own ethos. From this point of view one can consider that ethics is an act of self-creation in a continuous and relational process, opening up to an infinite horizon of possibilities. As Pereira (2009) said "Every human possibility and reality happens in this dialectic relationship between what I can become and transcends me and what I am and is immanent to me" (p. 7). In this sense ethics as nothing to do with a normative ethics (understood as a "science" of action which in the majority of times empties the subjective character of action), instead it implies an act of self-creation and self-development of all our capabilities and potential as human beings. This act of being means the always new and renewed possibility of building our self as a person, in a constant search of a "narrative identity" in which we are always rewriting our own history. As Pereira (2009) remarked "A person is not a mere productive entity, always building 'old things anew' from old materials, on the opposite, each act because it is always unprecedented from an absolute point of view, brings something new [...]" (p. 1). Thereby, the space of ethics is that of a construction of what each of us is or as the possibility to become always in relation. More precisely, ethics is the inner domain of each human being, where in such an ethos each person is ontological constituted and asserts itself as a person. It is in action, par excellence the place of ethical creativity that every situation is different, as there can be no fixed technique or standard routine for arriving at the appropriate action. It is in action and by action that creative ethics happens expressing in this way, the singularity of each being. As already mentioned according to Gonçalves (1998, pp. 57-58), action can be understood as: 
- The core experience of the human being although it does not limit itself only to the human being;

- Positive dynamism of development and affirmation of the value of reality;

- Openness to innovation and new experiences. Starting from what there is one open-up to new possibilities, therefore it is an experience of unity and unification in difference;

- A relation between all beings. As the ground is ontological and not anthropological, human beings do not find themselves in relation as other beings as if they were "alter egos", but they are also manifestations of the same being shared by all.

Ethics understood as this ontological experience of action is more related to movements of irradiation and openness than to norms or duties where what prevails is the cooperation and not the tireless struggle of some at the cost of the destruction or obliteration of others. As Henry remarked:

Ethics is the theory of action. Action implies an essential immediacy of life [...]. The task of ethics, in reality is to understand why there is an immanent teleology to life and how life is in fact which decides about its own action. (1989, p. 4)

Thus ethics is an incessant search for meaning, for us and for others, and in this search is a wisdom which is constituted in the very act of being, which is neither representative, nor exterior, but above all, it transforms and transfigures. It is through the act of being that one comes to life, not only our own life, but also the lives of all beings with whom one affectively shares the same life. It is from life that we receive this inaugural gift or as Blondel (1995) stated "There is always something" (p. 41) that "there is which give us each time the possibility of the act of being and of being in relation" (Levinas, 1971). The first relation is the relation with this gift without which no other relation would be possible and without this inaugural gift we could not exist. The second relation is the ethical capability of development. The relationship between these two moments is crucial and without this capability of ethical development this gift would be only virtual. And finally it is from this ethical capability that one is able to raise oneself and build the world, in the search of a "common place" (Glissant, 1990, p.187).

It is in this triple relationship that life affirms itself and ethics constitutes itself as the affirmation of a principle of kindness which animates everything and that in the face of an act of being elevates and vivifies ourselves. It is in this way that a relational poetics is built through the receiving of the gift of life and through the act of being ethical transforms, making the world possible as a continuous process of transfiguration and positive creation of everything which lives. On the one hand, ethics living as a relational poetics can be understood as an inter-relation, in the sense of an interdependence which constantly broadens the relations in which everybody's freedom is at the service of a common poetics, ephemeral and always in the process of building itself (Heidegger, 1987). On the other hand, ethics can also be understood as a principle of reflection which against all kinds of closeness is topographical, geographical, or cultural. Furthermore, it opens the relationship and the correlation with the other where life offers itself in each instant as a gift, always ready to be unveiled and to come into existence and opening itself to the constant call of the other.

\section{Conclusions}

Ethics has its own place and pertinence in our world and in business, but an ethics which has the human being as its main target can give neither final answers nor solutions to certain fields of reality which surpass it. In spite of business being a human activity, it cannot resume itself to a discussion about what is the best for 
human beings, because a satisfactory ethical theory can not only take into account the human being but it should have a consistent theory of action underneath.

The fact that ethics cannot be on the top list of the epistemological scale is one of the limits pointed to ethics, because:

- To ground ethics on the human nature is not taking into account that nature is an idea conceived by culture and that does not translate the whole of reality;

- With the idea of nature one articulates the scheme of the species and in it the autonomy and the specific difference of each species, which in reality means the subordination of the inferior to the superior;

- This contrast between the specific differences ends up by placing the human being in the centre of the universe and the differences remain with no guarantee of a true unity (Gonçalves, 1990).

If, on the other hand, we consider that ethics is still an expression of being, we are touching the universality of its grounding which in spite of valuing the human being does not contrast him/her with other beings, but places him/her in a closer relationship. Following from this, anthropology should be replaced in the knowledge scale and although business is a human activity, it only makes sense if it is developed in relation with all beings and not only the human beings.

Human action, which for instance, the business activity is only an expression, does not make sense if just understood in its dimension of a techne, but that dimension should be integrated in a larger and more embracing one which corresponds to the dynamism of being itself (Soares, 2008, pp. 1-2).

If it is possible to say that ideas such as rationality, agency, and relationship can be applied to corporations, it is also possible to say that they have ethical responsibilities (Soares, 2003). Nevertheless, those responsibilities go beyond self-interest or mere regulation, they should be integrated in a more inclusive project of making possible for the corporation to give answers not just to the market demanding, but to the demands which spring from life itself and produce a surplus of richness to all parts, including the universe.

\section{References}

Blondel, M. (1995). The action: Essay of a critical life and a science of practice (L'Action: Essai d'une critique de la vie et d'une science de la pratique). Paris: PUF.

Glissant, É. (1990). Poetique of relation (Poétique de la relation). Paris: Gallimard.

Gonçalves, J. C. (1990). Doing philosophy: How and where (Fazer Filosofia: Como e Onde)? Braga: Faculdade de Filosofia Universidade Católica.

Gonçalves, J. C. (1998). In praise of life and death: The environment-western culture in question (Em Louvor da Vida e da Morte: Ambiente-A cultura Ocidental em Questão). Lisboa: Ed. Colibri.

Heidegger, H. (1949). Letter on the humanism. In W. Kluback, \& J. T. Wilde (Eds.). New York: Twayne.

Heidegger, H. (1987). An introduction to metaphysics. In R. Manheim (Ed.). New Haven: Yale University Press.

Henry, M. (1989). What science does not know (Ce que la science ne sait pas). CERN Press Review, 289, 32-33.

Lévinas, E. (1971). Totality and infinity: An essay on exteriority (Totalité et Infini: Essai sur l'exteriorité). Paris: Biblio Essais.

Pereira, A. (2009). Ethics of Louis Lavelle (Da Ética de Louis Lavelle). Retrieved from http://www.lusosofia.net

Soares, C. (2003). Corporate versus individual moral responsibility. Journal of Business Ethics, 46, 143-150.

Soares, C. (2008). Corporate legal responsibility: A Levinasian perspective. Journal of Business Ethics, 81, 545-553. 